British Journal of Psychiatry (1987), 151, 266

\title{
Correspondence
}

Editor: Greg Wilkinson

Contents: Hostility and deliberate self-poisoning/ Self-poisoning and suicide attempts by burning/No fixed abode/Late paraphrenia or the paraphrenias/ Comparative trial of a new antidepressant/A comparative hospital survey of psychotropic drug prescribing/Compulsory detention of males of different ethnic groups/The psychological well-being of supporters of the demented elderly/Concept of mild endogenous depression/Tuberous sclerosis and the autistic syndrome/Delusional infestation in later life/Hysterical personality disorder/Capgras' syndrome in a patient with dementia/Trazodoneinduced mania/Long-term psychiatric patients in the community/Erotomania and cerebral dysfunction/ Italian psychiatry/Latitude and affective disorders.

\section{Hostility and Deliberate Self-Poisoning}

SIR: May I draw attention to another concept of 'hostility', additional to those covered by Farmer (Journal, May 1987, 150, 609-614). This is the concept of irritability. Farmer supplies four descriptions of factors covering the construct of hostility: aggression, attitude of dislike, anger, and a predisposition to behave in a hostile or aggressive manner. The concept that we introduced (Snaith \& Taylor, 1985) is that of irritability and, at our request, this was accepted as a new Medical Subject Heading, under the term 'Irritable mood', in the Index Medicus. In order that the term might be used in a standard way we supplied a definition: "Irritability is a feeling state characterised by reduced control over temper, which usually results in irascible verbal or behavioural outbursts, although the mood may be present without observed manifestation. It may be experienced as brief episodes in particular circumstances, or it may be prolonged and generalised. The experience of irritability is always unpleasant for the individual and overt manifestation lacks the cathartic effect of justified outbursts of anger".

Our interest in :his state had been aroused by Pitt's (1968) observation of its frequency in the setting of post-natal depression, and our own research into mood disorder following childbirth led to the development of a brief self-assessment scale, the Irrita- bility Depression and Anxiety (IDA) scale (Snaith et $a l, 1978)$. The article introducing that instrument described how we also had looked at the BussDurkee, the HDHQ, and other instruments but found that none fitted the state which we wished to delineate. The IDA scale has two irritability subscales (the outwardly-directed and the inwardlydirected irritability scales) and these, together with the depression and anxiety sub-scales, were published in the original article in order that they may be freely used-subject only to acknowledgement of copyright to The British Journal of Psychiatry (a convenient form with incorporated scoring device is available free of charge on application to myself). The first of our papers quoted above presents the validation of these sub-scales in four different studies and it was concluded that the outward-irritability scale is a homogeneous scale but that the inwardirritability scale is composed of two concepts; two of the four items composing it relate to suicidal selfharm and the other two items to a more general feeling of annoyance with oneself. If the IDA scale is to be used in research in the setting of suicide studies it is now advised that the inward-irritable scale is analysed by these two separate components.

Farmer has drawn attention to the diffuse concepts covered by different measuring instruments. We maintain that the IDA scale, with the modification just referred to, does provide a simple, acceptable set of measures and we hope that others will use it in suicide studies as well as all the other psychopathological and other states (such as post-natal depression, head injury, epilepsy, and drug withdrawal) in which the two aspects of irritability are a common and troublesome feature.

\section{Department of Psychiatry}

Phillip SNaIth

\section{St John's University Hospital}

Leeds LS9 7TF

\section{References}

PrtT, B. (1968) Atypical depression following childbirth. British Journal of Psychiatry, 114, 1325-1335.

SNAITH, R. P. \& TAYLOR, C. M. (1985) Irritability: definition, assessment and associated factors. British Journal of Psychiatry, 147, 127-136. 
- Constantopoulos, A. A., Jardine, M. Y. \& McGuffin, P (1978) A clinical scale for the self-assessment of irritability. British Journal of Psychiatry, 132, 164-171.

\section{Self-Poisoning and Suicide Attempts by Burning}

SIR: The use of the term suicide 'epidemic' is fashionable. Both Farmer (Journal, May 1987, 150, 609614) and Zemishlany et al (Journal, May 1987, 150, 704-706) use the term, in the former article to describe incidence trends in the general population, and in the latter to focus on the timing of three suicide attempts in a psychiatric hospital.

One should ask whether the 'epidemic model' of suicide is the appropriate concept for the phenomena being described. Strictly speaking, such a model would require the criteria of an epidemic, such as the identification of a 'host', a 'vector', and a 'mode of transmission' of a 'noxious agent', to be fulfilled.

Currently, there appears to be a resurgence of research interest in the 'Werther effect', referring to the phenomenon where newspaper publicity of suicides is apparently associated with an increase in suicide rates (Phillips, 1974). Phillips coined this term 200 years after Goethe's romantic novel The Sorrows of the Young Werther was banned in a number of centres in Europe for allegedly providing a model for imitative suicides. Some caution needs to be exercised in the labelling of increased suicide rates or of suicide clusters as "epidemics". Implied in the designation of a suicide "epidemic" based on imitation are preventative measures (such as the literary censorship that befell Goethe's novel), one being the suggestion that "educators, policy makers, and journalists may wish to consider ways of reducing public exposure to stories, both general and specific, about suicide (Phillips \& Carstensen, 1986). While this recommendation may have superficial appeal, and may eventually be based on experimental evidence, the imitative propagation hypothesis to explain national suicide rate increases still awaits replicable proof.

Turning to suicide clusters, suggestible individuals, whether 'normal' young people or vulnerable adults in institutional settings such as hospitals or prisons, are more likely to be influenced by the basic psychological process of identification than by suggestion or imitation (Halasz, 1987) and the recommendation of "group sessions after a suicidal case in order to neutralise the identification with the act by suggestible patients" (Zemishlany et al) seems a clinical imperative.

However, this is a clinical recommendation, not in need of an epidemic model of explanation. Rather, it underlines the need for clinicians to recognise individual vulnerability in normal developmental phases, as occurs in childhood and adolescence, as well as in stress-induced regressed adult states brought about by illness, or dramatic changes in personal degrees of freedom.

George Halasz

Austin Hospital

Heidelberg

Victoria 3084

Australia

\section{References}

HaLASZ, G. (1987) Imitation, suggestion, identification - possible psychological factors in suicidal behaviour. Presented at the 23rd Annual Congress, The Royal Australian and New Zealand College of Psychiatrists, Auckland, New Zealand, 10-15 May.

PHILLIPS, D. P. (1974) The influence of suggestion on suicide: substantive and theoretical implications of the Werther effect. American Sociological Review, 39, 340-354.

Phillus, D. P. \& Carstensen, M. S. (1986) Clustering of teenage suicides after television news stories about suicide. New England Journal of Medicine, 315, 685-689.

\section{No Fixed Abode}

SIR: We read with interest the recent report by Herzberg (Journal, May 1987, 150, 621-627). We compared four groups of patients: urban fixed abode, urban 'no fixed abode' (NFA), and rural and semi-rural consecutive male psychiatric admissions, with 50 patients in each cell (O'Shea et al, 1983). This study also used retrospective case-note information.

Poor employment records and early parental separation were common in the NFA group; rural men generally live with others, the homeless tend to be single (NFA: married, 3; single, 40; separated, 6; divorced, 1; widowed, 0 ); age did not differentiate any of the groups; all groups shared "chronic schizophrenia' and 'alcoholism' as the chief diagnostic categories; the strong impression was gained that alcohol-related difficulties were generally underestimated; patients in the NFA group were more likely to have legal records; standard diagnostic methods were hardly ever employed; physical pathology was common and widespread in all four groups; routine ancillary tests were not readily available; and most patients came from the lower socioeconomic levels of society.

Specifically, the physical findings among the NFA group were: eight men had chronic obstructive airways disease, mostly with acute exacerbations at the time of admission; three, one with a past history of cerebrovascular accident, were hypertensive, and all of these were on hypotensive drugs; the man with the stroke had a residual hemiparesis and epilepsy; two other cases had experienced alcohol-related convulsions; a fourth man's fits were found to be due to an 